\title{
Remodeling of the antegonial angle region in the human mandible: A panoramic radiographic cross-sectional study
}

\author{
Sujoy Ghosh ${ }^{1}$, Manoj Vengal ${ }^{2}$, Keerthilatha M Pai ${ }^{3}$, Kumar Abhishek ${ }^{4}$
}

${ }^{1}$ BDS, MDS, Center for Dental Education and Research, All India Institute of Medical Sciences, New Delhi

${ }^{2}$ BDS, MDS, Associate Professor, Department of Oral Medicine \& Radiology, Manipal College of Dental Sciences, Manipal, Karnataka India

${ }^{3}$ BDS, MDS, Associate Dean, Manipal College of Dental Sciences, Manipal, Karnataka India

${ }^{4}$ BDS, Senior Research Fellow, Center for Dental Education and Research, All India Institute of Medical Sciences, New Delhi India

Correspondence:

Center for Dental Education and Research

All India Institute of Medical Sciences

New Delhi-110029

India

sujoy68@rediffmail.com

Ghosh S, Vengal M, Pai KM, Abhishek K. Remodeling of the antegonial angle region in the human mandible: A panoramic radiographic crosssectional study. Med Oral Patol Oral Cir Bucal. 2010 Sep 1;15 (5):e802-7. http://www.medicinaoral.com/medoralfree01/v15i5/medoralv15i5p802.pdf

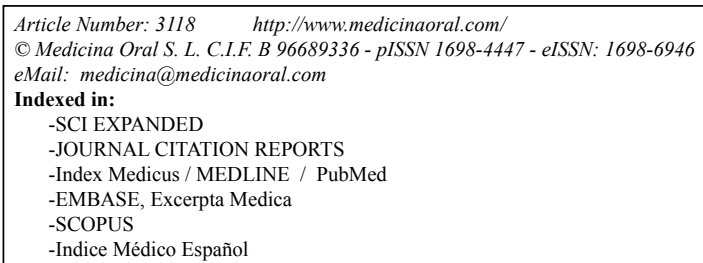

\begin{abstract}
Objectives: This study analyzed changes in the antegonial region in relation to age, gender, and dental status. Study design: A total of one thousand patients (five hundred males and five hundred females), who were prescribed panoramic radiograph for various purposes were included in the study. The patients were categorized according to age, gender and dentition status. Panoramic radiographs were traced and antegonial angles and depths were measured.

Results: A trend of decrease in the antegonial angle and increase in antegonial depth with age was observed in both males and females. Furthermore there were differences between right and left side antegonial angle and depth, with left side angle more than right and right side depth more than left. There was a significant decrease in the values of antegonial angle and significant increase in the values of antegonial depth as the dentition status changed from completely dentulous to partially dentulous and from partially dentulous to completely edentulous state.

Conclusions: The antegonial angle decreases with the advancing age and thereby increases the antegonial depth. Similar trends are seen when teeth are lost. Furthermore there is an inherent asymmetry in the antegonial region in right and left side.
\end{abstract}

Key words: Antegonial region, orthopantomograph, age, dentition status. 


\section{Introduction}

The bone remodeling is a continuous and complex process which occurs through our life. During an individual's life, the morphological changes undergone by the mandible are thought to be influenced by dental status and the age of the patient (1). The various remodeling fields in the mandible which undergo changes include the gonial region, antegonial region, condyle and ramus.

The upward curving of the inferior border of the mandible anterior to the angular process (gonion) is known as antegonial notching. It lies at the junction of body and the ramus. The strategic position of the shape has been considered an indicator of how the mandible grew, or perhaps more importantly, will grow (2). There are significant differences in mandibular growth direction between subjects with deep mandibular antegonial notches and shallow mandibular antegonial notches (3). Kolodziej et al. also suggested that antegonial notch depth, when extreme in magnitude, might be used to predict facial growth (4). Morphological alterations in the antegonial region have been researched thoroughly in young individuals but little research has been done for this aspect in adults (5).

The present study was conducted to better understand the alteration in the antegonial region and to correlate with various parameters like age, sex and dentition status.

\section{Materials and Methods}

The study was conducted in the Dept. of Oral Medicine and Radiology, Manipal College of Dental Sciences, Manipal, Karnataka, India. A total of one thousand patients (500 males and 500 females), who were prescribed panoramic radiographs for various purposes were included in the study. Their demographic data and dental status were recorded in a proforma specially designed for the study. The subjects were divided based on age into 5 groups of 200 patients each (100 males and 100 females), with the following age groups: 20-29 years, $30-39$ years, $40-49$ years, $50-59$ years and 60 years and above. The following were excluded from the study: patients with gross facial asymmetry, patients with various anomalies affecting cranio-facial region and mandible, various systemic and local disorders affecting growth of the cranio-facial region, patients who were undergoing or had undergone any orthognathic surgery, patients who had undergone any other major surgery and/ or radiotherapy related to head and neck, patients with symptoms of tempromandibular joint disorders (TMD), patients with any history of facial trauma.

Institutional Ethical committee approval was received. An orthopantomograph (OPG) was taken in the standard manner using a Planmeca PM2002CC panoramic machine (Planmeca Oy, Helsinki, Finland) according to the manufacturer's reference guide. Various lines (midsagittal plane, canine guidance line, and Frankfort horizontal plane) were defined using the reference standards to avoid positioning errors when taking the radiographs. Only high-quality radiographs were considered for the study. Radiographs with various errors were excluded. After excluding radiographs, the sample size was kept constant by including the radiographs of additional patients who came in for panoramic radiographs, provided that they met the inclusion and exclusion criteria.

A single examiner determined the antegonial angle by tracing two lines parallel to the antegonial region that intersected at the deepest point of the antegonial notch. The angle was measured using a protractor. The antegonial depth was measured as the distance along a perpendicular line from the deepest point of the notch concavity to a tangent through the inferior border of the mandible (Fig. 1).

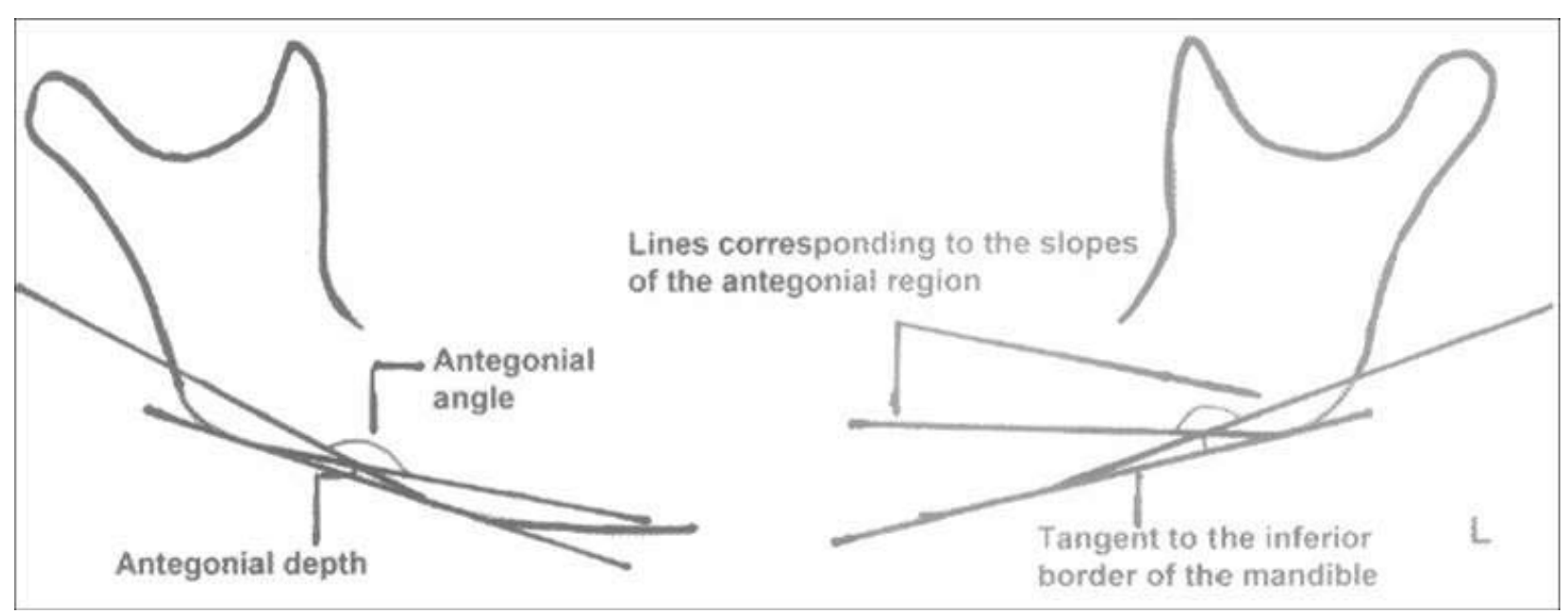

Fig. 1. Method of measuring Antegonial angle and depth. 
The various values of the measurements were entered in tabulated form in SPSS software version 11 (SPSS Inc, Chicago, Ill). The results were analyzed using ANOVA test. The $p$ value was established at 0.05 for measuring the degree of significance. For those variables, where the test of homogeneity of variances showed a significant value equal to or less than 0.05 , a non-parametric test of Kruskal-Wallis was applied for measuring the degree of significance. A paired ' $t$ ' test was applied for determining the degree of variation between right and left side antegonial angles and depths. Post-hoc test was done by using Bonferroni test wherever required. For non parametric test values, multiple comparisons were done by using Wilcoxon-Ranksum test with Bonferroni correction. Multivariate analysis was further done.

One hundred OPGs were retraced after an interval of 1 month for calculating intra-observer variability. Various antegonial angles and depths were again measured by the same examiner. The results were compared with the older values. The significance was detected using reliability analysis using the same SPSS software.

\section{Results}

In both males and females, on right as well as left sides, there was no statistically significant change in the value of the antegonial angle with respect to age, although a trend of decrease in the antegonial angle with age was observed. The mean difference between the antegonial angle value at age of 20-29 years and 60 years and above was $1.33^{\circ}$ in males and $0.93^{\circ}$ in females. Similarly with respect to the antegonial depth, the mean value did not change significantly with age (Table 1), although, a general trend in increase in the value was observed. The mean increase was $0.15 \mathrm{~mm}$ from age group of 20-29 years to 60 years and above in males while in females the mean increase was $0.13 \mathrm{~mm}$ (Table 1).

Differences between values of antegonial angle and depth between males and females are also noted. Females had higher values of antegonial angles as compared to males. With respect to antegonial depths females had smaller values as compared to males (Table 1).

There were differences in the values of antegonial angle and depth between right and left sides in both males and

Table 1. Antegonial angles and depths in different age groups with difference between males \& females.

\begin{tabular}{|c|c|c|c|c|c|c|c|}
\hline & \multirow{4}{*}{$\begin{array}{c}\text { Age group } \\
\text { (in years) }\end{array}$} & $\begin{array}{c}\text { Mean angle } \\
\text { (std. } \\
\text { Deviation) } \\
\text { [in degrees] }\end{array}$ & $\begin{array}{c}\text { Mean depth } \\
\text { (std. } \\
\text { Deviation) } \\
\text { [in mm] }\end{array}$ & $\begin{array}{c}\text { Mean angle } \\
\text { (std. } \\
\text { Deviation) } \\
\text { [in degrees] }\end{array}$ & $\begin{array}{c}\text { Mean } \\
\text { depth (std. } \\
\text { Deviation) } \\
\text { [in mm] }\end{array}$ & $\begin{array}{c}\text { Difference be- } \\
\text { tween male \& } \\
\text { female angle } \\
\text { values } \\
\text { (p values) }\end{array}$ & $\begin{array}{c}\text { Difference } \\
\text { between male } \\
\text { \& female depth } \\
\text { values (p value) }\end{array}$ \\
\cline { 2 - 9 } $\begin{array}{l}\text { Right ante- } \\
\text { gonial angle } \\
\text { and depth }\end{array}$ & $\mathbf{2 0 - 2 9}$ & $170.09(8.58)$ & $1.36(1.21)$ & $173.20(7.45)$ & $0.80(0.92)$ & $3.11^{\circ}(0.007)^{\mathrm{a}}$ & $0.56 \mathrm{~mm}(0.001)^{\mathrm{b}}$ \\
\cline { 2 - 9 } & $\mathbf{3 0 - 3 9}$ & $171.36(8.60)$ & $1.14(1.91)$ & $173.32(7.63)$ & $0.83(1.01)$ & $1.96^{\circ}(0.090)^{\mathrm{a}}$ & $0.31 \mathrm{~mm}(0.045)^{\mathrm{a}}$ \\
\cline { 2 - 9 } & $\mathbf{4 0 - 4 9}$ & $169.30(9.27)$ & $1.45(1.32)$ & $172.61(8.67)$ & $0.87(1.08)$ & $3.31^{\circ}(0.010)^{\mathrm{a}}$ & $0.58 \mathrm{~mm}(0.001)^{\mathrm{b}}$ \\
\cline { 2 - 9 } & $\mathbf{5 0 - 5 9}$ & $169.42(9.55)$ & $1.34(1.23)$ & $171.46(7.90)$ & $1.06(1.01)$ & $2.04^{\circ}(0.101)^{\mathrm{a}}$ & $0.28 \mathrm{~mm}(0.160)^{\mathrm{b}}$ \\
\cline { 2 - 9 } & $\mathbf{6 0 ~ \& ~ a b o v e}$ & $168.03(8.12)$ & $1.59(1.14)$ & $171.69(7.49)$ & $1.00(0.97)$ & $3.66^{\circ}(0.001)^{\mathrm{a}}$ & $0.59 \mathrm{~mm}(0.000)^{\mathrm{a}}$ \\
\hline
\end{tabular}

$\mathrm{p}=0.155 \mathrm{k} \quad \mathrm{p}=0.126 \quad \mathrm{p}=0.317 \mathrm{a} \quad \mathrm{p}=0.291$

\begin{tabular}{|c|c|c|c|c|c|c|c|}
\hline & \multirow{4}{*}{$\begin{array}{c}\text { Age group } \\
\text { (in years) }\end{array}$} & $\begin{array}{c}\text { Mean angle } \\
\text { (std. } \\
\text { Deviation) } \\
\text { [in degrees] }\end{array}$ & $\begin{array}{c}\text { Mean depth } \\
\text { (std. } \\
\text { Deviation) } \\
\text { [in mm] }\end{array}$ & $\begin{array}{c}\text { Mean angle } \\
\text { (std. } \\
\text { Deviation) } \\
\text { [in degrees] }\end{array}$ & $\begin{array}{c}\text { Mean } \\
\text { depth (std. } \\
\text { Deviation) } \\
\text { [in mm] }\end{array}$ & $\begin{array}{c}\text { Difference be- } \\
\text { tween male \& } \\
\text { female angle } \\
\text { values } \\
\text { (p values) }\end{array}$ & $\begin{array}{c}\text { Difference } \\
\text { between male } \\
\text { \& female depth } \\
\text { values (p value) }\end{array}$ \\
\cline { 2 - 9 } $\begin{array}{l}\text { Left ante- } \\
\text { gonial angle } \\
\text { and depth }\end{array}$ & $\mathbf{2 0 - 2 9}$ & $170.19(8.64)$ & $0.80(0.92)$ & $174.30(6.59)$ & $0.70(0.87)$ & $4.20^{\circ}(0.000)^{\mathrm{b}}$ & $0.62 \mathrm{~mm}(0.001)^{\mathrm{b}}$ \\
\cline { 2 - 9 } & $\mathbf{3 0 - 3 9}$ & $172.17(7.44)$ & $0.83(1.01)$ & $174.36(6.71)$ & $0.70(0.93)$ & $2.19^{\circ}(0.030)^{\mathrm{a}}$ & $0.34 \mathrm{~mm}(0.019)^{\mathrm{a}}$ \\
\cline { 2 - 9 } & $\mathbf{4 0 - 4 9}$ & $171.54(8.06)$ & $0.87(1.08)$ & $174.76(7.06)$ & $0.68(0.96)$ & $3.22^{\circ}(0.003)^{\mathrm{a}}$ & $\begin{array}{c}0.51 \mathrm{~mm}(0.002) \\
\mathrm{b}\end{array}$ \\
\cline { 2 - 9 } & $\mathbf{5 0 - 5 9}$ & $171.16(8.14)$ & $1.06(1.01)$ & $172.93(7.02)$ & $0.89(0.96)$ & $1.77^{\circ}(0.101)^{\mathrm{a}}$ & $0.27 \mathrm{~mm}(0.117)^{\mathrm{b}}$ \\
\cline { 2 - 9 } & $\mathbf{6 0 ~ \& ~ a b o v e}$ & $169.49(8.48)$ & $1.00(0.97)$ & $173.94(6.56)$ & $0.75(0.86)$ & $4.45^{\circ}(0.000)^{\mathrm{b}}$ & $0.64 \mathrm{~mm}(0.000)$ \\
\end{tabular}

$\mathrm{p}=0.135 \mathrm{a} \quad \mathrm{p}=0.234 \mathrm{a} \quad \mathrm{p}=0.380 \mathrm{a} \quad \mathrm{p}=0.492 \mathrm{a}$

a: As determined by ANOVA test

b: As determined by Kruskall-Wallis test. Wherever Kruskal wallis test applied mean to be considered as median 
females. It was observed that except for the age groups of 20-29 years [in both males ( $\mathrm{p}$ values 0.986 and 0.560 respectively for antegonial angle and depth) and females ( $p$ values 0.079 and 0.206 respectively for antegonial angle and depth)], 30-39 years age group [only males ( $\mathrm{p}$ values 0.115 and 0.193 respectively for antegonial angle and depth)] and 50-59 years [males only for antegonial depth (p value 0.054$)$ ], there was a statistically significant difference between values in the right and left, antegonial angles and depths in both sexes.

In this study there was a statistically significant decrease in the value of antegonial angles from completely dentulous patients to partially edentulous patients and from partially edentulous patients to completely edentulous patients. With respect to the antegonial depth there was a statistically significant increase in the values from completely dentulous patients to partially edentulous patients and from partially dentulous patients to completely edentulous patients (Table 2).

The multivariate analysis also confirmed the results which were analyzed in the previously mentioned tables. The regression coefficient and adjusted regression coefficient values for antegonial angle and antegonial depth suggested non significant $p$ values with respect to the age groups. With respect to the comparison between both the genders, regression coefficient (with standard error) and adjusted regression coefficient (with standard error) values for right antegonial angle, left antegonial angle, right antegonial depth and left antegonial depth were: $2.81(0.529)$ and $2.87(0.526) ; 3.16(0.475)$ and 3.23 (0.473); - $0.46(0.709)$ and $-0.47(0.142) ;-0.47(0.066)$ and $-0.48(0.065)$ respectively. These values suggested significant (with $\mathrm{p}<0.05$ significance) difference between male \& female angles and depths. The multivariate analysis also confirmed that there was significance change in the values of antegonial angle and depth when dentition status changes from dentulous state to partially dentulous state and then to completely edentulous state. With respect to the antegonial angle, regression coefficient (with standard error) and adjusted regression coefficient (with standard error): (i) right side, values were -1.88 (0.564), -3.05 (0.931) and -1.71 (0.633), -2.85 (1.061); (ii) left side, values were $-1.28(0.512),-2.42$ $(0.845)$ and $-1.64(0.569),-2.96(0.954)$ respectively. With respect to the antegonial depth, regression coefficient (with standard error) and adjusted regression coefficient (with standard error): (i) right side, values were 0.21 (0.762), 0.40 (0.125) and 0.20 (0.085), 0.41 (0.087); (ii) left side, values were 0.19 (0.071), $0.30(0.118)$ and 0.23 (0.079), $0.38(0.132)$ respectively. The values compared the completely dentuluous state to partially dentulous and completely edentulous state respectively. The intra-class correlation coefficient (for reliability analysis) for right and left antegonial angles and depths were $0.94,0.91,0.93$ and 0.90 respectively.

Table 2. Antegonial angle and depth with relation to dentition status.

\begin{tabular}{|c|c|c|c|c|c|}
\hline & \multirow{2}{*}{$\begin{array}{l}\text { Dentition } \\
\text { status }\end{array}$} & \multicolumn{2}{|c|}{ Males } & \multicolumn{2}{|c|}{ Females } \\
\hline & & $\begin{array}{c}\text { Mean angle } \\
\text { (std. deviation) }\end{array}$ & $\begin{array}{c}\text { Mean depth } \\
\text { (std. deviation) }\end{array}$ & $\begin{array}{c}\text { Mean angle } \\
\text { (std. deviation) }\end{array}$ & $\begin{array}{c}\text { Mean depth } \\
\text { (std. deviation) }\end{array}$ \\
\hline \multirow{3}{*}{$\begin{array}{l}\text { Right } \\
\text { side }\end{array}$} & Dentulous & $170.73^{\circ}\left(8.79^{\circ}\right)$ & $1.25 \mathrm{~mm}(1.23 \mathrm{~mm})$ & $173.75^{\circ}\left(7.29^{\circ}\right)$ & $\begin{array}{c}0.75 \mathrm{~mm} \\
(0.94 \mathrm{~mm})\end{array}$ \\
\hline & $\begin{array}{l}\text { Partially } \\
\text { dentulous }\end{array}$ & $169.06^{\circ}\left(8.84^{\circ}\right)$ & $1.43 \mathrm{~mm}(1.20 \mathrm{~mm})$ & $171.84^{\circ}\left(8.21^{\circ}\right)$ & $\begin{array}{c}0.98 \mathrm{~mm} \\
(1.03 \mathrm{~mm})\end{array}$ \\
\hline & $\begin{array}{l}\text { Completely } \\
\text { edentulous }\end{array}$ & $167.67^{\circ}\left(8.96^{\circ}\right)$ & $1.67 \mathrm{~mm}(1.30 \mathrm{~mm})$ & $170.52^{\circ}\left(7.62^{\circ}\right)$ & $\begin{array}{c}1.19 \mathrm{~mm} \\
(1.02 \mathrm{~mm})\end{array}$ \\
\hline \multicolumn{2}{|c|}{ p value } & $0.042^{*},(1,3)^{*}$ & $0.043^{*}, @(1,3)^{*}$ & $0.008^{*}, \mathrm{k}(1,2 ; 1,3)^{*}$ & $0.004^{*} @(1,3)^{*}$ \\
\hline \multirow{3}{*}{$\begin{array}{l}\text { Left } \\
\text { side }\end{array}$} & Dentulous & $171.69^{\circ}\left(8.23^{\circ}\right)$ & $1.10 \mathrm{~mm}(1.16 \mathrm{~mm})$ & 174.94 & $\begin{array}{c}0.63 \mathrm{~mm} \\
(0.83 \mathrm{~mm})\end{array}$ \\
\hline & $\begin{array}{c}\text { Partially } \\
\text { dentulous }\end{array}$ & $170.63^{\circ}\left(8.01^{\circ}\right)$ & $1.27 \mathrm{~mm}(1.15 \mathrm{~mm})$ & 173.62 & $\begin{array}{c}0.81 \mathrm{~mm} \\
(0.96 \mathrm{~mm})\end{array}$ \\
\hline & $\begin{array}{l}\text { Completely } \\
\text { edentulous }\end{array}$ & $168.51^{\circ}\left(8.61^{\circ}\right)$ & $1.51 \mathrm{~mm}(1.16 \mathrm{~mm})$ & 172.80 & $\begin{array}{c}0.89 \mathrm{~mm} \\
(0.93 \mathrm{~mm})\end{array}$ \\
\hline \multicolumn{2}{|c|}{ p value } & $0.005^{*}, @(1,3)^{*}$ & $0.046^{*} @(1,3)^{*}$ & $0.050^{*, \mathrm{k}}(1,3)^{*}$ & $0.042^{*}, \mathrm{k}(1,3)^{*}$ \\
\hline
\end{tabular}

@: ANOVA test. K: Kruskal Wallis test. Wherever Kruskal Wallis test applied mean to be considered as median. Dentulous state: 1. Partially edentulous state: 2 . Edentulous state: 3 . Values in parentheses in the rows associated with p value describe Bonferroni correction (in cases of non parametric tests, Wilcoxon Ranksum test with Bonferroni correction) * significant. 


\section{Discussion}

Despite several articles analyzing antegonial region in the first and second decades of life for evaluation and prediction of mandibular growth, little is known concerning its remodeling in the ageing and in the edentulous patients. Our paper brings some light to an issue that is not yet fully understood nor studied, i.e. the remodeling of the mandibular antegonial region with age, gender and dental status.

The reliability of OPGs in measuring the various angulations and vertical dimensions has been discussed by various authors. There is acceptable reproducibility for the vertical and angular variables for group comparisons, provided head positioning is standardized and kept constant (6). It is stated that despite the unreliability of horizontal measurements, angular measurements might be performed with high reliability in OPG. Furthermore, it is also proved that a slight misalignment of the head, which occurs frequently in everyday practice, does not significantly affect vertical measurements in the posterior mandible or maxilla, or in the anterior mandible, and minor antero-posterior shifts and tilts are associated with a variation of less than $2 \%$ for mandibular measurements in the vertical plane $(5,7)$. Thus method of using OPG for determination of the antegonial angle and depth in the present study could be considered reliable.

In this study no statistical significant relation was observed between the mean antegonial angles and depths with respect to the age, though antegonial angles decreased with the age while the mean antegonial depths increased with age (Table 1). Females had higher values of antegonial angles as compared to males. While the reverse was true regarding antegonial depths, which was smaller in females as compared to males (Table 1). The results of this study were consistent with the results of a study of Dutra et al. who did not find significant correlations between age and change in antegonial angles and depths (5). They showed that antegonial angles in males (mean $160.80^{\circ}$ ) was significantly smaller than in females (mean $165.08^{\circ}$ ) and that the antegonial depths were significantly greater for males than females. This was also observed in the present study. But the mean absolute values of the antegonial angles $\left(170.27^{\circ}\right.$ for males while $173.25^{\circ}$ for females) in the present study were about $8^{\circ}-10^{\circ}$ higher than Dutra et al. study.

However, while comparing the absolute values of antegonial angle on right and left sides, left side values were more than the right side values in each group (Table 1). Opposite was true regarding the antegonial depth, as right side values were more than left side. The mean difference in the antegonial angles in each age groups were as following: $20-29$ years: $0.56^{\circ}, 30-39$ years: $0.92^{\circ}, 40-49$ years: $2.19^{\circ}, 50-59$ years: $1.60^{\circ}, 60$ years and above: $1.86^{\circ}$. The mean difference in antegonial depths in each age groups were as following: $20-29$ years: 0.07 $\mathrm{mm}, 30-39$ years: $0.11 \mathrm{~mm}, 40-49$ years: $0.23 \mathrm{~mm}, 50$ 59 years: $0.18 \mathrm{~mm}, 60$ years and above: $0.22 \mathrm{~mm}$. These results are consistent with result of Preston B et al. who reported that mean dimension of right mandibular antegonial notches were greater than the corresponding mean dimension recorded for the left antegonial notches (8).

While comparing the antegonial angle with respect to dentition status, on both right and left sides and in both sexes, there was a statistically significant decrease in the value of the antegonial angle from completely dentulous state to partially dentulous state and then to completely edentulous state while there was a statistical increase in the values of antegonial depth with edentulousness (Table 2). The mean decrease in the value of the antegonial angle from the dentulous state to partially dentulous state and then to completely edentulous state was $1.36^{\circ}, 1.74^{\circ}$ and $1.62^{\circ}, 1.06^{\circ}$ respectively for males and females. The mean increase in the value of the antegonial depth from the dentulous state to partially dentulous state and then to completely edentulous state was 0.18 $\mathrm{mm}, 0.24 \mathrm{~mm}$ and $0.20 \mathrm{~mm}, 0.14 \mathrm{~mm}$ respectively for males and females.

With respect to relation with dentition status, present study showed similar results as were shown by Dutra et al. (5). Edentulous individuals had smaller mean antegonial angle than partially dentate group, who had smaller value than completely dentulous individuals while edentulous individuals had greater mean antegonial depth than partially dentate group, who had greater value than dentulous individuals.

With regard to the remodeling changes occurring in the antegonial region it is stated that the bone deposition occurs throughout the inferior border of the mandible except in the antegonial region, where there could be a resorptive pattern, which would decrease the antegonial angle and increase the antegonial depth (1). The increase in antegonial depth and decrease in the antegonial angle in the edentulous patients might represent a resorptive pattern in the edentulous mandibles (5). Further it is also stated that this resorptive pattern might be accentuated by deposition that probably takes place anterior to the antegonial region (1). It has been further stated that when the growth of the mandibular condyle fails to contribute to the lowering of the mandible, the masseter and the medial pterygoid, by the continued growth, cause, the bone in the region of the angle to grow downward producing antegonial notching $(3,8,9)$. In other words, the resorption that normally occurs below the gonial angle does not occur. A relative tension is generated between the angle and the muscle sling, in which it is suspended, such that bone deposition occurs in the area under the angle posterior to the notch (8).

The difference between males and females could be 
explained by the gender differences affecting the bone metabolism and the variation of the action of muscular masses attached in this region $(5,10)$.

Differences in the right as well as left side antegonial region suggest that resorption of the right antegonial region occurred more as compared to the left antegonial region, hence proving the inherent nature of asymmetry of the human mandible. It further strengthens findings that even in the absence of malformation or skull base asymmetry, the mandible may be physiologically asymmetric (11).

The ultimate shape of a fully grown mandible is the result of genetic determinants that express themselves under the influence of the functional environment. The relatively complex shape of the mandible reflects the multiplicity of the functions. It said that the antegonial notch is probably a good indicator of how the mandible grew (8).

The values of the intra-class coefficients (for reliability analysis) for the left and right gonial angles and depths were very high, proving the reliability of the method used in the study. Further, the method employed in the study utilized OPG which were prescribed by various departments for their requirements and coincidentally used for the study purpose; hence there was no additional exposure to the patients as recommended (12).

The results of the study have some important implications. The study results provide insight into remodeling of antegonial region. Although much is known about the growth and development of the mandible, its remodeling is still not understood completely. Some osteotomies for orthognathic surgery are performed in the antegonial region, and a resorptive pattern in this region has implications when performing this surgery in edentulous patients. Also, the differences in the antegonial region between males and females can be useful as a forensic tool for gender determination. The observations of the present study further enrich the field of Anthropometry. Cortical width measurements have been used in the antegonial region to predict if patients are at risk of osteoporosis, but since the resorptive pattern is influenced by dental status, measurements in the antegonial region may be unsuitable for osteoporosis assessment.

\section{Conclusion}

The results of this study demonstrated that the antegonial regions undergo remodeling with advancing age. The dentition status demonstrated a much more important role in the remodeling process as compared to age. The antegonial angle decreased with advancing age and thereby increased the antegonial depth. Similarly, the antegonial angles decreased as teeth were lost and thereby increased the antegonial depths. Females had deeper antegonial notches as compared to males. An inherent asymmetry in the antegonial regions between right and left sides was one of the major conclusions of the present study.

\section{References}

1. Enlow DH, Bianco HJ, Eklund S. The remodeling of the edentulous mandible. J Prosthet Dent. 1976;36:685-93.

2. Lambrechts AH, Harris AM, Rossouw PE, Stander I. Dimensional differences in the craniofacial morphologies of groups with deep and shallow mandibular antegonial notching. Angle Orthod. 1996;66:265-72.

3. Ali IM, Yamada K, Hanada K. Mandibular antegonial and ramus notch depths and condylar bone change. J Oral Rehabil. 2005;32:1-6.

4. Kolodziej RP, Southard TE, Southard KA, Casko JS, Jakobsen JR. Evaluation of antegonial notch depth for growth prediction. Am J Orthod Dentofacial Orthop. 2002;121:357-63.

5. Dutra V, Yang J, Devlin H, Susin C. Mandibular bone remodelling in adults: evaluation of panoramic radiographs. Dentomaxillofac Radiol. 2004;33:323-8.

6. Larheim TA, Svanaes DB. Reproducibility of rotational panoramic radiography: mandibular linear dimensions and angles. Am J Orthod Dentofacial Orthop. 1986;90:45-51.

7. Xie Q, Soikkonen K, Wolf J, Mattila K, Gong M, Ainamo A. Effect of head positioning in panoramic radiography on vertical measurements: an in vitro study. Dentomaxillofac Radiol. 1996;25:61-6.

8. Preston B, Al-Sehaibany F, Salem O. The morphology of the mandibular antegonial notches and facial symmetry. J Clin Pediatr Dent. 2002;26:155-60.

9. Becker MH, Coccaro PJ, Converse JM. Antegonial notching of the mandible: an often overlooked mandibular deformity in congenital and acquired disorders. Radiology. 1976;121:149-51.

10. Xie QF, Ainamo A. Correlation of gonial angle size with cortical thickness, height of the mandibular residual body, and duration of edentulism. J Prosthet Dent. 2004;91:477-82.

11. Captier G, Lethuilier J, Oussaid M, Canovas F, Bonnel F. Neural symmetry and functional asymmetry of the mandible. Surg Radiol Anat. 2006;28:379-86.

12. Martínez Beneyto Y, Alcaráz Banos M, Pérez Lajarin L, Rushton VE. Clinical justification of dental radiology in adult patients: a review of the literature. Med Oral Patol Oral Cir Bucal. 2007;12:E24451 . 